\title{
Restoring initial conditions in a deep argillaceous formation with induced suction on retrieval
}

\author{
Nuria Sau $^{1,2} *$ Enrique Romero ${ }^{1,2}$, and Hervé Van Baelen ${ }^{3}$ \\ ${ }^{1}$ Centre Internacional de Mètodes Numèrics en Enginyeria CIMNE, Barcelona, Spain \\ ${ }^{2}$ Universitat Politècnica de Catalunya UPC, Barcelona, Spain \\ ${ }^{3}$ ONDRAF/NIRAS, Brussels, Belgium
}

\begin{abstract}
The deep and plastic Ypresian clays (Ycs) are one of the potential host rock formations in Belgium for the geological disposal of heat-emitting radioactive waste. Consequently, their thermo-hydromechanical behaviour has to be exhaustively studied at different depths. With this aim and considering that there is no underground research facility, deep core samples of Ycs have been retrieved between 300 and $450 \mathrm{~m}$ depth. The water-undrained sampling induces high matric suctions on the retrieved samples despite their nearly saturated state. Microstructural features, and particularly the larger dominant pore sizes with relatively low air-entry values, may also affect this induced suction. An experimental campaign has been launched to analyse the induced suction at different depths, which is complemented with pore size distributions carried out with mercury intrusion porosimetry. The study is accompanied by a constant volume test, in which a retrieved cylindrical sample with high initial suction is subjected to positive water pressure at the bottom boundary. The evolution of pore water pressure and total stress at different heights allows detecting the development of effective stress (swelling pressure) close to the initial suction. Finally, the paper emphasises the importance of following adequate experimental protocols on these high-suction samples to restore in situ conditions.
\end{abstract}

\section{Introduction and background information}

The Ypresian clays Ycs are a deep plastic argillaceous formation, which-together with the Boom Clay-are currently considered in Belgium for the geological disposal of heat-emitting radioactive waste. Unlike the Boom Clay, there is no underground research laboratory enabling a more accessible sampling. Therefore, to study the thermo-hydro-mechanical properties and their variability with depth, core samples of Ycs have been retrieved between 300 and $450 \mathrm{~m}$ below ground at Kallo (Belgium).

The water-undrained unloading upon sampling induces matric suction despite the saturated or nearly saturated state of the material after retrieval, which is associated with the null effective stress change during the process (e.g. [1,2]). This suction increase is particularly remarkable in the water-undrained and deep sampling in argillaceous formations [3]. Within this context, Table 1 summarises the sampling depth, the measured total suction, $\psi$, and the degree of saturation, $S_{r}$, of retrieved samples from different potential argillaceous host rock formations in Europe and reported by various authors.

It is expected that the microstructural featuresparticularly the largest dominant pore sizes with low-air entry values-also have some impact on these high- induced suctions. Table 1 also incorporates information on the mono-modal or multi-modal character of the pore size distribution (PSD) by mercury intrusion porosimetry, the maximum dominant pore size, $\phi_{\max }$, and the air-entry value (AEV) of these dominant pores according to the Young-Laplace equation for capillary pressure. As indicated by [4], the induced suction should be compared with the capability of the porous mediamainly associated with the AEV-to sustain this value under saturated conditions. If the induced suction is larger than the $\mathrm{AEV}$, then air is expected to enter the soil during retrieval (causing the decrease of $S_{r}$ ). If not, then the material is able to sustain the induced suction, and $S_{r}=1$ will be maintained.

It is important to highlight that besides the induced suction due to total stress release, some small soil water evaporation during storage may occur rendering further suction increase. This behaviour can be observed in Table 1 on the first three low-porosity formations with high $\mathrm{AEV}$, in which total suctions greater than the estimated ones by the depth of retrieval and larger than the AEVs can be achieved with small water content losses.

The plastic Boom Clay is the most similar formation to Ypresian clays, albeit at a shallower depth. As can be observed in the table, the suction measured in Boom Clay (equivalent to the induced one at the sample depth) can be sustained due to its relatively high AEV (4.8

*Corresponding author: nuria.sau@upc.edu 
$\mathrm{MPa}$ ) and $S_{r}$ can be kept close to one. The deeper Ycs display a different response associated with their larger pores: the higher induced suctions cannot be sustained due to the lower AEVs of the formation.

This paper sheds light on these as-retrieved suctions with depth by relying on a series of tests carried out on Ycs by [5]. The objective of this study focuses on

- comparing the estimated induced matric suctions and the measured ones throughout the sampling depth;
- studying the influence of the microstructural features on the measured matric suctions after retrieval; and

- highlighting the importance of following strict protocols on these high-suction samples to restore in situ conditions.

Table 1. Data from different argillaceous host rock formations in Europe.

\begin{tabular}{|c|c|c|c|c|c|c|c|}
\hline Material & Ref. & Depth (m) & $\psi(\mathrm{MPa})$ & $S_{r}$ & PSD shape & $\phi_{\max }(\mathrm{nm})$ & $\operatorname{AEV}(\mathrm{MPa})$ \\
\hline \multirow{3}{*}{$\begin{array}{l}\text { Opalinus clay } \\
\text { (Switzerland) }\end{array}$} & {$[6]$} & 879 & 4 & Close to 1 & \multirow{3}{*}{ Mono-modal } & 16 & 18 \\
\hline & [7] & 936 & 44 & Close to 1 & & $<8$ & $>37$ \\
\hline & [8] & $855-891$ & 67 & 0.73 & & 7 & 42 \\
\hline \multirow{3}{*}{$\begin{array}{l}\text { Brown Dogger } \\
\text { (Switzerland) }\end{array}$} & [6] & 776 & 5 & Close to 1 & \multirow{3}{*}{ Mono-modal } & 20 & 14 \\
\hline & [9] & 781 & 37 & $0.95-1.0$ & & 22 & 13 \\
\hline & [10] & $767-778$ & 45 & 0.89 & & 16 & 18 \\
\hline $\begin{array}{l}\text { COx claystone } \\
\text { (France) }\end{array}$ & [11] & 479 & 34 & 0.77 & Mono-modal & 32 & 9.1 \\
\hline $\begin{array}{l}\text { Boom Clay } \\
\text { (Belgium) }\end{array}$ & [9] & 223 & 2.5 & Close to 1 & Mono-modal & 70 & 4.8 \\
\hline $\begin{array}{c}\text { Ypresian clays } \\
\text { (Belgium) }\end{array}$ & {$[5]$} & $283-390$ & $1.5-3.2$ & $0.82-1.0$ & $\begin{array}{l}\text { Multi-modal and } \\
\text { mono-modal }\end{array}$ & $81-2075$ & $0.15-3.9$ \\
\hline
\end{tabular}

\section{Suction and microstructural depth profiles in Ypresian clays}

The Ycs are a sequence of marine sediments deposited during the Ypresian Age (spanning the time between 56 to $47.8 \mathrm{Ma}$ ). An exhaustive experimental study on core samples retrieved along $100 \mathrm{~m}$ depth (from 283 to 390 $\mathrm{m})$ at Kallo (Belgium) has been reported by [5] to assess the natural variability of the mineralogy, bulk density and microstructural features.

This section summarises selected results on six core samples using Mercury Intrusion Porosimetry (MIP) tests and measurements of the initial total suction using a chilled-mirror dew-point psychrometer (WP4). The results will help better understanding the role played by the microstructural features.

The induced matric suction after retrieval can be estimated assuming perfect sampling (no mechanical disturbances during sampling, storage and trimming), which implies that the release of mean total stress, $\Delta p$, is equal to the decrease in pore water pressure, $\Delta u_{w}$ (i.e. null effective stress change during the process). Total and effective vertical stresses, $\sigma_{v i}$ and $\sigma_{v i}{ }^{\prime}$, and the pore water pressure, $u_{w i}$, at in situ conditions were determined assuming a homogeneous bulk density throughout the studied depth $\left(1.97 \mathrm{Mg} / \mathrm{m}^{3}\right.$ [12]) with a water-table elevation at ground surface. The same earth pressure coefficient at rest $K_{0}{ }^{S C}$ [13] was considered, assuming a yield stress ratio $Y S R=1.4$ [12] and a drained friction angle $\phi^{\prime}=16^{\circ}[14]$ along the $100 \mathrm{~m}$ of Ypresian clays:

$$
K_{0}^{S C}=\left(1-\sin \phi^{\prime}\right) \sqrt{Y S R}=0.86
$$

The mean effective and total stresses, $p_{i}^{\prime}$ and $p_{i}$, at in situ conditions were

$$
p_{i}^{\prime}=\frac{1}{3}\left(1+2 K_{0}^{S C}\right) \sigma_{v i}^{\prime} ; p_{i}=p_{i}^{\prime}+u_{w i}
$$

After retrieval, $p_{f}=0$, and the decrease in pore water pressure is equal to $\Delta u_{w}=-p_{i}=-\left(p_{i}^{\prime}+u_{w i}\right)$. Therefore, the matric suction after retrieval was determined as

$$
s=-u_{w f}=-\left(u_{w i}+\Delta u_{w}\right)
$$

An alternative to these analyses when the degree of saturation is slightly less than one could be using Skempton's pore pressure parameters [15]. For example, the isotropic pore pressure parameter for incompressible solid can assumed $B=0.91$ based on an average bulk compressibility of the soil skeleton $2.0 \times 10^{-6} \mathrm{~m}^{2} / \mathrm{kN}$ and average porosity $n=0.44$ along a water undrained path to restore in situ conditions [5].

Particular care has been taken to evaluate the matric suction, $s$, from the measured (with WP4) total initial suction, $\psi$, and to consider an estimated osmotic suction, $\pi$, that evolves with the degree of saturation, $S_{r}$. The degree of saturation has been introduced to take into account solvent evaporation and the corresponding increase in salinity. The pore water of Ycs is mainly 
composed of sodium chloride $\mathrm{NaCl}$ and sodium sulphate $\mathrm{Na}_{2} \mathrm{SO}_{4}$. The osmotic component was determined using the following expression [16] that considers salt mass concentration, $C_{0}$, of the heteroionic Ycs solution.

$$
\pi=68.3 \mathrm{kPa}\left(\frac{1}{S_{r}} \frac{C_{0}}{1 g / L}\right)^{1.014}=\frac{541 \mathrm{kPa}}{S_{r}^{1.014}}
$$

where $C_{0}=7.7 \mathrm{~g} / \mathrm{L}$ was assumed homogeneous throughout the profile.

Figure 1a plots the depth profile of the estimated induced matric suctions on each core sample (labels on the plot), as well as the measured total suctions corrected by the osmotic component. It is worth noting that the estimated values are consistently higher than the measured ones. Moreover, core samples after retrieval consistently displayed degrees of saturation below 0.95 , as plotted in Figure 1b. This fact is probably associated with the high matric suctions induced on retrievalbetween 2.5 and $3.5 \mathrm{MPa}$ - and the pore size distribution of Ycs. The results of MIP tests on freeze-dried samples allow plotting the depth profiles in Figure $2 \mathrm{a}$ of the maximum dominant pore sizes. The corresponding airentry values AEVs based on these dominant pore sizes and estimated using the Young-Laplace equation are shown in Figure 2b. (a) $s(\mathrm{MPa})$

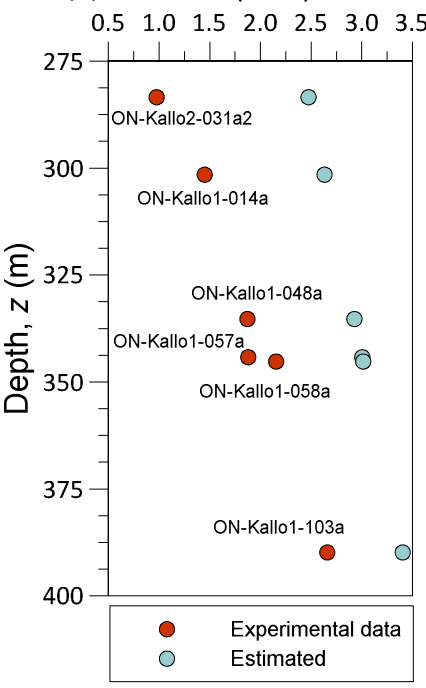

(b) $\quad \operatorname{Sr}(-)$

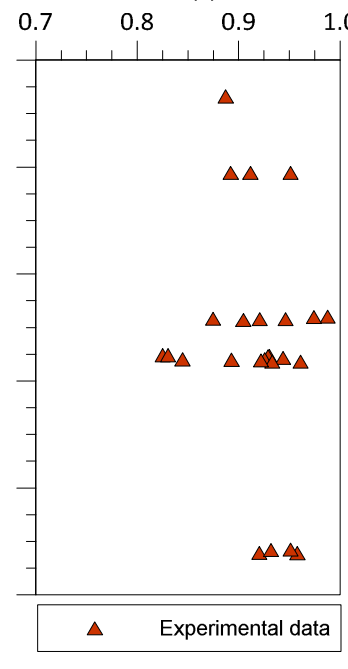

Fig. 1. Depth profiles: (a) induced (estimated) matric suctions on retrieval and measured ones; and (b) measured degrees of saturation.

All core samples display multi-modal pore size density functions except one mono-modal at $390 \mathrm{~m}$ depth (ON-Kallo1-103a), with dominant maximum pore sizes ranging between $100 \mathrm{~nm}$ and $2 \mu \mathrm{m}$, and AEVs between 0.15 and $3.15 \mathrm{MPa}$. The smallest AEV corresponds to a sandy sample and the largest to the clayey sample with the mono-modal distribution.

AEVs are consistently lower than the estimated matric suctions, even in the case of the sample with mono-modal distribution and dominant pore size of $100 \mathrm{~nm}$. Consequently, and despite the careful sampling and trimming, some air is expected to enter the soil. This air induces some small swelling of the material. Typically a compression deformation of around $0.77 \%$ has been observed under oedometer conditions on restoring the in situ vertical effective stress [5].

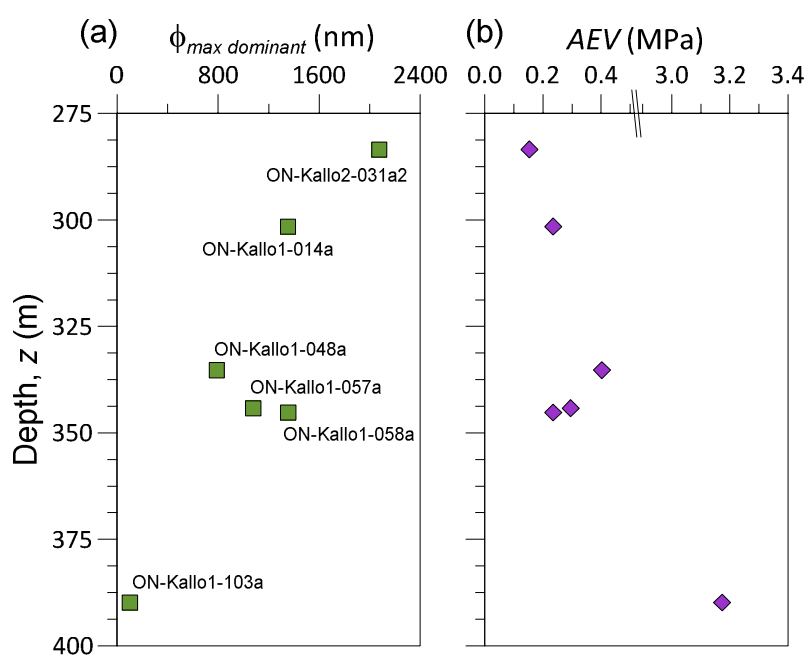

Fig. 2. Depth profiles: (a) maximum dominant pore sizes from MIP; and (b) estimated air-entry values using Young-Laplace equation.

It is important to point out that it is anticipated that the sample will not become homogeneously desaturated during preparation. Only the external surface of the $100 \mathrm{~mm}$ core may be the most susceptible zone to air entry and drying during trimming. Afterwards, vacuum packing will allow the suction, and therefore the degree of saturation, to be homogenised.

\section{Sample tested under constant volume}

The constant volume (isochoric) test was performed on a sample retrieved at $334.8 \mathrm{~m}$ depth (core ON-Kallo1$048 \mathrm{a})$. The Ycs at this depth present $48 \%$ clay minerals, which are dominated by smectite $(25.4 \%)$ and illite $(13.4 \%)$. Non-clayey fraction is mainly constituted by quartz $(35 \%)$, alkali feldspar $(3.6 \%)$ and plagioclase (5.1\%) [17]. Table 2 summarises the soil properties, the initial state of the sample and the AEV determined by MIP.

Figure 3 shows the multi-modal pore size distribution. The maximum intruded void ratio was 0.686 , which indicated a quite connected pore network close to the void ratio reported in Table 2. Three dominant pore sizes were detected with a maximum value of $780 \mathrm{~nm}$ associated with a low air-entry value of $0.40 \mathrm{MPa}$. The induced matric suction on retrieval (close to $3 \mathrm{MPa}$ as shown in Figure 1a) cannot be sustained, and air entry is expected to occur $\left(S_{r}=0.875\right)$.

Figure 4 displays the water retention curve on drying in terms of matric suction. The total suction results using WP4 psychrometer have been corrected for the osmotic component according to Equation (4). Results have been fitted to the van Genuchten equation [18]. The plot also includes the initial state of the sample that approximately matches the fitted curve. The figure also provides water retention results obtained from MIP. The procedure 
proposed by [19] has been followed to ensure that measured data and estimated data from MIP are consistent at $s \approx 3 \mathrm{MPa}$ (i.e. within the capillary domain).

Table 2. Properties and the initial state of the tested material.

\begin{tabular}{|l|c|}
\hline \multicolumn{1}{|c|}{ Soil properties } & $\begin{array}{c}\text { Core ON-Kallo1-048a } \\
\text { (depth: } 334.8 \text { to 335.8 m) }\end{array}$ \\
\hline Bulk density, $\rho$ & $1.91 \mathrm{Mg} / \mathrm{m}^{3}$ \\
\hline Density of solids, $\rho_{s}$ & $2.72 \mathrm{Mg} / \mathrm{m}^{3}$ \\
\hline Water content, $w$ & $25.2 \%$ \\
\hline Void ratio, $e$ & 0.785 \\
\hline Degree of saturation, $S_{r}$ & $87.5 \%$ \\
\hline Total suction, $\psi$ & $2.4 \mathrm{MPa}$ \\
\hline Matric suction, $s$ & $1.8 \mathrm{MPa}$ \\
\hline Air-entry value, $A E V$ & $0.40 \mathrm{MPa}$ \\
\hline Particle sizes $<40 \mu \mathrm{m}$ & $99.8 \%$ \\
\hline Particle sizes $<2 \mu \mathrm{m}$ & $31.3 \%$ \\
\hline Liquid limit, $w_{L}$ & $134 \%$ \\
\hline Plasticity index, $P I$ & $105 \%$ \\
\hline
\end{tabular}

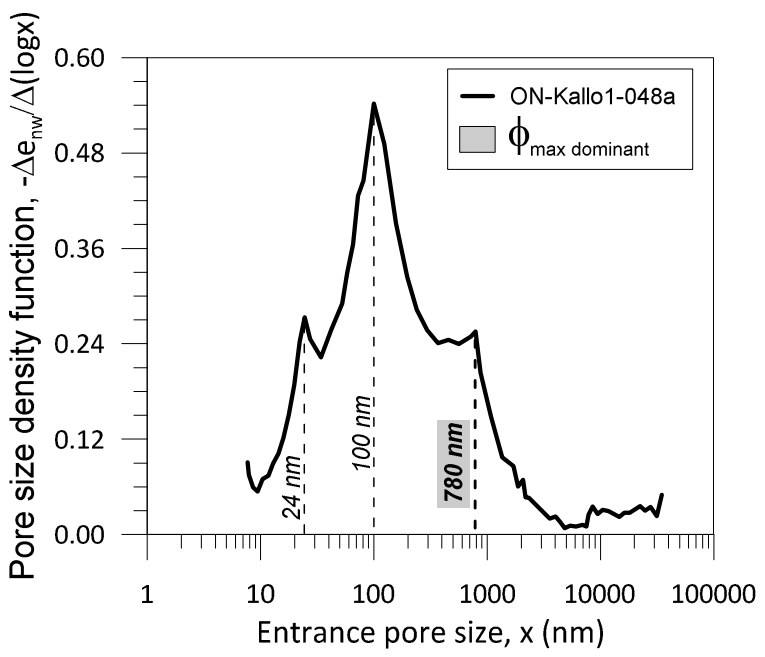

Fig. 3. PSD obtained by MIP on a freeze-dried sample from core ON-Kallo1-048a.

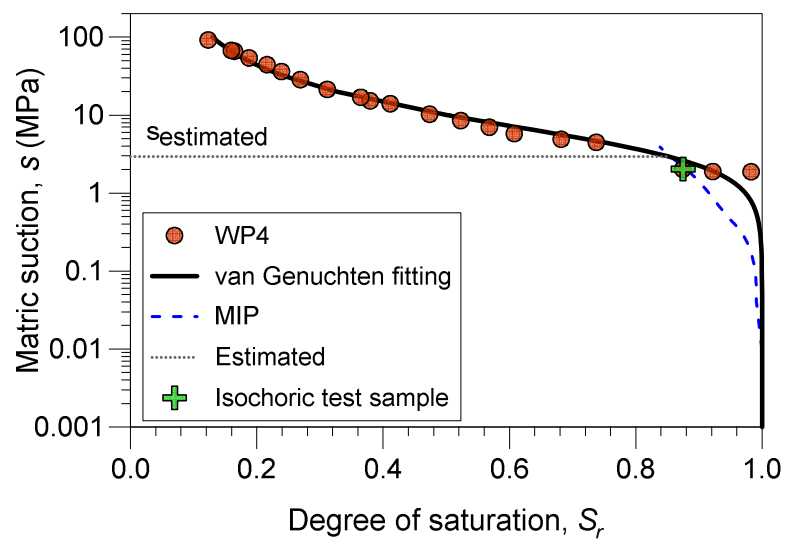

Fig. 4. Drying retention curves of core ON-Kallo1-048a in terms of matric suction. The plot includes the fitted curve, the water retention curve deduced from MIP data and the initial state of the sample.

\section{Swelling pressure test by reducing the induced suction on retrieval}

The soil sample previously described has been installed in a cylindrical constant volume cell $(75 \mathrm{~mm}$ in diameter and $100 \mathrm{~mm}$ high). The sample displays bedding planes orthogonal to the axis of symmetry of the cell. The aim of the test focuses on measuring the final vertical and horizontal effective stresses developed on reducing the induced suction associated with deep retrieval and some drying. At constant volume and $S_{r}$ close to one, the initial effective stress is expected to coincide with the final one after contact with water and the application of backpressure. The initial effective stress (at null total stress and $S_{r} \approx 1$ ) corresponds to $\sigma_{i}^{\prime}=-u_{w i}=s_{i}$ (i.e. $\sigma_{i}^{\prime}=1.8 \mathrm{MPa}$ according to Table 2).

The isochoric cell was developed by [20], updated by [12] and recently improved with total stress sensors by [5,21]. Figure 5 shows two schematic cross-sections of the isochoric cell. It allows continuous monitoring at specific points of the boundaries of pore water pressures $\left(P w_{1}\right.$ and $P w_{2}$ at 75 and $25 \mathrm{~mm}$ from the bottom, respectively), temperatures $\left(T_{1}\right.$ and $\left.T_{2}\right)$ and total stresses $\left(P_{1}\right.$ and $P_{3}$ at mid-high on opposite sides, and $P_{2}$ at the top of the sample). The hydraulic boundary conditions (top and bottom valves, $u_{u}$ and $u_{b}$ ) are independently controlled using two volume/pressure controllers.
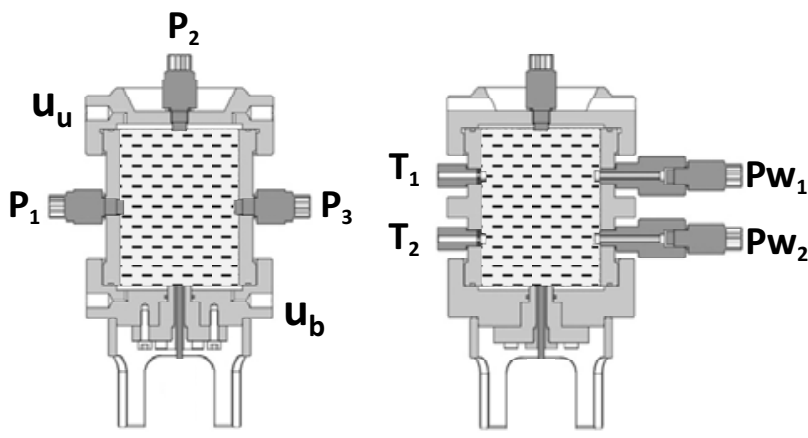

Fig. 5. Schematics of the improved isochoric cell with pore pressure transducers $\left(P w_{i}\right)$, total stress sensors $\left(P_{i}\right)$, thermocouples $\left(T_{i}\right)$, and water inlet $\left(u_{b}\right)$ and outlet $\left(u_{u}\right)$.

The hydration of the soil sample has been performed by applying a step-wise water pressure increase $0.1,0.3$, 0.5 and $1 \mathrm{MPa}$ at the bottom valve $\left(u_{b}\right)$, while the upper valve $\left(u_{u}\right)$ has been kept under atmospheric conditions. At the end of the hydration, the upper valve $\left(u_{u}\right)$ was closed, ensuring uniform water backpressure of $1 \mathrm{MPa}$ in the sample. Figure 6 and Figure 7 show the time evolution of pore water pressures and total stresses, respectively, during the different steps. As observed in Figure 6, it took some time for the transducers to record positive water pressures after applying the water backpressure at the bottom of the sample $\left(P w_{2}\right.$ after 6 days and $P w_{l}$ after 19 days). This delay in the response is associated with different aspects. On the one hand, the initial suction needs some time to develop into the positive range (saturation of the material). On the other hand, additional time is required to fill the lines and porous discs that interact with the transducer, particularly when the sensors are placed in a horizontal 
orientation with the possibility of trapping air. Given this experience, pre-filling the connector and transducer with water during the assembly of the cell will overcome such delays. The steady-states recorded by the water pressure transducers with $u_{u}$ valve at atmospheric pressure appear to follow a linear pore pressure distribution with height (consistent with a uniform water permeability). Once $u_{u}$ is closed, $P w_{1}$ and $P w_{2}$ show a relatively rapid increase to the target backpressure associated with a correct saturation of the sample.

The time-evolution of total stresses is consistent with the backpressure applied at the bottom of the sample during the different steps. The development of total stresses is related to the reduction of suction at constant volume conditions, as well as to the backpressure applied (constant effective stress). Once $u_{u}$ is closed, and the equalisation of pore water pressures is reached, the values of swelling pressure (total stresses minus pore pressures) can be obtained. Some anisotropy is observed during the saturation and suction reduction process, since a maximum vertical effective stress of $1.23 \mathrm{MPa}\left(P_{2}\right)$ in the direction orthogonal to the bedding planes is detected. The horizontal effective stresses reached values of 0.45 and $0.33 \mathrm{MPa}\left(P_{1}\right.$ and $\left.P_{3}\right)$.

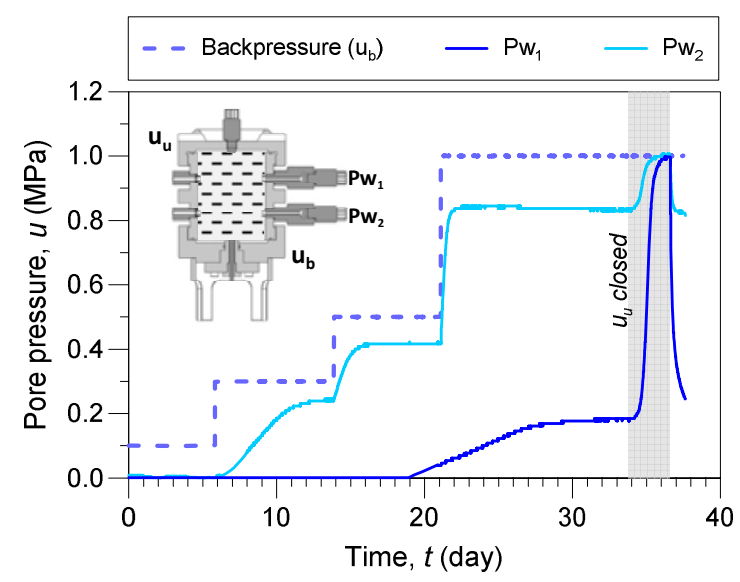

Fig. 6. Time evolution of pore water pressures at different locations during the hydration and backpressure steps.

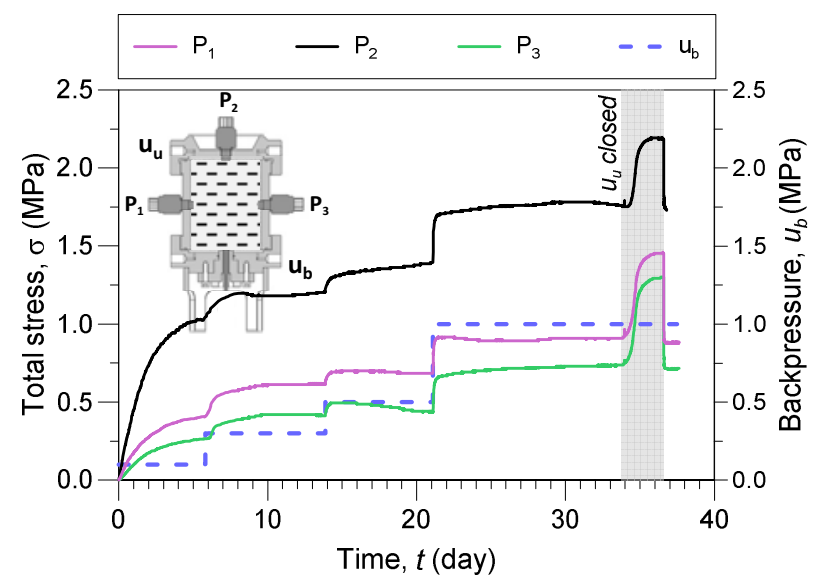

Fig. 7. Time evolution of total stresses at different locations during the hydration and backpressure steps.
Table 3 summarises the applied hydraulic boundary conditions and the maximum pore water pressures and total stresses measured during each step. The maximum vertical effective stress of $1.23 \mathrm{MPa}$ (swelling pressure at the final step) is close to the induced (initial) matric suction of 1.8 MPa (Table 2).

Table 3. Pore water pressures $P w_{i}$ and total stresses $P_{i}$ at the end of the backpressure $\left(\mathrm{u}_{\mathrm{b}}\right)$ steps. All units in MPa.

\begin{tabular}{|c|c|c|c|c|c|c|}
\hline $\mathrm{u}_{\mathrm{b}}$ & $\mathrm{u}_{\mathrm{u}}$ & $\mathrm{Pw}_{1}$ & $\mathrm{Pw}_{2}$ & $\mathrm{P}_{1}$ & $\mathrm{P}_{2}$ & $\mathrm{P}_{3}$ \\
\cline { 1 - 5 } 0.1 & \multirow{4}{*}{0.3} & 0.00 & 0.00 & 0.40 & 1.03 & 0.26 \\
\cline { 1 - 5 } & & 0.00 & 0.24 & 0.61 & 1.20 & 0.41 \\
\cline { 1 - 5 } 0.5 & & 0.04 & 0.42 & 0.68 & 1.39 & 0.44 \\
\cline { 1 - 5 } 1 & & 0.19 & 0.84 & 0.91 & 1.76 & 0.74 \\
\hline 1 & Closed & 1.00 & 1.00 & 1.45 & 2.23 & 1.33 \\
\hline
\end{tabular}

At the end of the test, the backpressure has been quickly reduced in one step, followed by the opening of $u_{u}$ and $u_{b}$ valves to atmospheric pressure. Then the soil sample has been carefully removed from the cell, displaying a slight swelling. Three specimens were immediately trimmed at different heights for total suction measurement. The final induced matric suction on water undrained unloading is approximately constant throughout the sample height, displaying values 0.78 , 0.84 and $0.64 \mathrm{MPa}$. The average induced matric suction is also close to the average value of swelling pressure (effective stress) measured in the test (around 0.7 MPa).

\section{Concluding remarks and comments on restoring in situ conditions}

The plastic and deep Ypresian clays Ycs are currently considered in Belgium-together with the Boom Claypotential argillaceous formations for the geological disposal of heat-emitting radioactive waste. Selected experimental results from an exhaustive test programme reported by [5] on Ycs core samples retrieved along $100 \mathrm{~m}$ depth (from 283 to $390 \mathrm{~m}$ ) at Kallo (Belgium) are used in the current study. The data have allowed comparing the estimated induced matric suctions on water undrained sample retrieval-assuming perfect sampling-and the measured ones in the laboratory after careful sample extraction and trimming.

The depth profiles of the estimated induced matric suction on retrieval, as well as the measured total suction corrected by the osmotic component, show that the estimated values-between 2.5 and $3.5 \mathrm{MPa}-$ are consistently higher than the measured ones-between 1.0 and 2.7 $\mathrm{MPa}$. This fact has led to the assumption that such a high induced matric suction has not been able to be sustained by the size of the largest dominant pores. This is the rationale behind the completion of the study with mercury intrusion porosimetry tests on freeze-dried samples to analyse the influence of these largest pores with the lowest air entry values AEVs.

Most studied core samples display multi-modal pore size density functions with maximum pore sizes ranging 
between $100 \mathrm{~nm}$ and $2 \mu \mathrm{m}$, and AEVs between 0.15 and 3.15 MPa. The AEVs are consistently lower than the estimated matric suctions. It is anticipated that these large pores desaturate (inducing some air entry) and consequently some small expansion of the sample. Moreover, core samples after retrieval consistently display degrees of saturation below 0.95 .

A constant volume test has been performed on a sample retrieved at mid-depth of the formation with an initial matric suction of $1.8 \mathrm{MPa}$ and degree of saturation 0.875 . The aim of this test focuses on measuring the final vertical and horizontal effective stresses developed on reducing the induced suction associated with deep retrieval and some drying. Some anisotropy is observed during the saturation and suction reduction process, since a maximum vertical effective stress of $1.23 \mathrm{MPa}-$ close to the initial matric suction-in the direction orthogonal to the bedding planes is detected. In contrast, the horizontal effective stresses reached values of 0.33 and $0.45 \mathrm{MPa}$. The final matric suction after fast (water undrained) unloading is approximately constant throughout the sample height (between 0.64 and 0.84 $\mathrm{MPa}$ ), which is similar to the mean swelling pressure measured in the test $(0.69 \mathrm{MPa})$.

The induced suction on water undrained retrieval should be considered for the definition of the stress paths to follow since samples can undergo swelling and possible degradation on contact with water at low stresses [4]. Samples should be loaded to total stress slightly higher than the in situ effective stress, and only then, placed in contact with synthetically prepared water at atmospheric pressure and equivalent osmotic suction.

\section{Acknowledgements}

The authors wish to acknowledge the financial support of ONDRAF/NIRAS (Belgium) through a $\mathrm{PhD}$ collaboration agreement with 'International Centre for Numerical Methods in Engineering' CIMNE (Spain) within the context of the Project 'Thermal aspects and their coupled HM effects on Ypresian clays and Boom Clay' CCHO 2016-0206/00/02 (2016-2020).

\section{References}

1. A. W. Skempton, V. A. Sowa, Géotechnique 13, 269 (1963).

2. I. G. Doran, V. Sivakumar, J. Graham, A. Johnson, Géotechnique 50, 189 (2000).

3. P. Delage, T. Le, A.-M. Tang, Y.-J. Cui, X.-L. Li, Géotechnique 57, 239 (2008).

4. A. Ferrari, E. Romero, Geophys. Monogr. Ser. Am. Geophys. Union (2019).

5. N. Sau, Thermo-Hydro-Mechanical Behaviour of Deep Argillaceous Formations (in Progress), 2020.

6. E. Romero, R. Gómez, Water and Air Permeability Tests on Deep Core Samples from Schlattingen SLA1 Borehole. NAB 13-51 (Wettingen, Switzerland, 2013).

7. E. Romero, L. Gónzalez-Blanco, Complementary Water and Air Permeability Tests on Core Samples from Schlattingen SLA-1 Borehole. NAB 15-06 (2015).

8. A. Ferrari, L. Laloui, in Multiphysical Test. Soils Shales. Springer Ser. Geomech. Geoengin., edited by L. Laloui and A. Ferrari (Springer, Berlin, Heidelberg, 2013), pp. 57-58.

9. L. Gonzalez-Blanco, E. Romero, C. Jommi, X. Li, X. Sillen, Geomech. Energy Environ. 6, 81 (2016).

10. A. Ferrari, V. Favero, P. Marschall, L. Laloui, Int. J. Rock Mech. Min. Sci. 72, 61 (2014).

11. P. Delage, H. Menaceur, A.-M. Tang, J. Talandier, in 3rd Eur. Conf. Unsaturated Soils. E-UNSAT 2016 (E3S Web of Conferences, Paris, France, 2016), p. 18004

12. A. Lima, Thermo-Hydro-Mechanical Behaviour of Two Belgian Clay Formations: Boom and Ypresian Clays, Universitat Politècnica de Catalunya, 2011.

13. G. Della Vecchia, A. Lima, C. Jommi, E. Romero, in Proc. 5th Int. Conf. Unsaturated Soils (Barcelona, Spain, 2010), pp. 803-809.

14. X. P. Nguyen, Y. J. Cui, A. M. Tang, X. L. Li, Ypresian, THM Behaviour of Clay. 4th Ypresian Clay Meeting (Barcelona, Spain, 2011).

15. A. W. Skempton, Géotechnique 4, 143 (1954).

16. C. Mata, E. Romero, A. Ledesma, in 3rd Int. Conf. Unsaturated Soils, UNSAT, edited by J. F. T. Jucá, T. M. P. de Campos, and F. A. M. Marinho (Recife, Brazil, 2002), pp. 283-288.

17. G. Mertens, R. Adriaens, Analysis Report of the Bulk and Clay Mineralogy of 21 ON-Kallo-1 Samples (2018).

18. M. T. van Genuchten, Soil Sci. Soc. Am. J. 44, 892 (1980).

19. E. Romero, P. H. Simms, Geotech. Geol. Eng. 26, 705 (2008).

20. J. Muñoz, E. E. Alonso, A. Lloret, Géotechnique 59, 293 (2009).

21. N. Sau, E. Romero, H. Van Baelen, in 7th Int. Symp. Deform. Charact. Geomaterials (EDP Sciences, Glasgow, United Kingdom, 2019), pp. 1-6. 